\title{
Sulfur Structure and Stable Isotopic Analysis of the Blackstone Band of the Jurassic Aged Kimmeridge Clay Formation
}

Molly D O'BeIRne ${ }^{1,2}$, Josef P Werne ${ }^{1}$, WILLIAM P. GilhoOly III ${ }^{3}$, Alice BosCo-SANTOS ${ }^{3}$, Morgan R. RAVEN $^{2}$, AlEX L. SESSIONS ${ }^{4}$, BART E. VAN DONGEN ${ }^{5}$

${ }^{1}$ Department of Geology \& Environmental Science, University of Pittsburgh, Pittsburgh, PA 15260, USA, mdobeirne@pitt.edu; jwerne@pitt.edu

${ }^{2}$ Department of Earth Science, University of California, Santa Barbara, CA, USA, raven@ucsb.du

${ }^{3}$ Department of Earth Sciences, Indiana University-Purdue University Indianapolis, Indianapolis, IN 46202, USA, wgilhool@iupui.edu; alicebosco@gmail.com

${ }^{4}$ Division of Geological and Planetary Sciences, California Institute of Technology, Pasadena, CA 91125, USA, als@gps.caltech.edu

${ }^{5}$ School of Earth and Environmental Sciences, University of Manchester, Manchester, UK,

bart.VanDongen@manchester.ac.uk

The sulfur cycle and specifically organically-bound sulfur (OS) has been of long standing interest in the Geosciences not only because it acts as a sink for organic carbon, constituting the second largest pool of reduced sulfur in the environment, but also because of its impacts on petroleum occurrence and generation. The utility of the OS record for (paleo)environmental reconstruction and oil - source rock correlations has been shown. However, details of the various factors affecting the distribution and stable sulfur isotope compositions $\left(\delta^{34} S\right)$ of OS remain to be resolved before widspread application may occur. Accordingly, we investigated the OS record of the Blackstone Band of the Jurassic aged Kimmeridge Clay Formation - where the high organic carbon content $(>34 \%)$ has been attributed to the reaction between reduced sulfur and carbohydrates during early diagnesis (i.e., the formation of OS). In particular, we focused on determining the structural and stable sulfur isotopic relationships among sulfur pools before and after anhydrous, continuous-flow pyrolysis. We present results from FTIR, sulfur K-edge XANES, bulk and compoundspecific sulfur isotope analysis (CSSIA) of bulk sulfur species - total sulfur, pyrite sulfur and OS, as well as solvent-soluble bitumen compounds and solvent-insoluble/kerogen pyrolysates. These analyses revealed distinct differences among the sulfur pools that are related to sample stratigraphic position and corresponding paleoenvironmental conditions. 